\section{Research on financial platform of railway freight supply chain based on blockchain}

\author{
Peng Xie \\ Institute of Computing Technology, \\ China Academy of Railway Sciences Corporation Limited, Beiing, China$$
\text { Qiang Chen and Ping Qu }
$$$$
\text { Haoji Railway Corporation Limited, Beijing, China, and }
$$$$
\text { Jianping Fan and Zhijun Tang }
$$ \\ Beijing Eigpay Information Technology Corporation Limited, Beijing, China
}

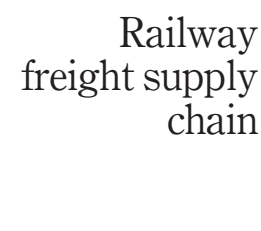

Received 28 September 2020 Revised 14 October 2020 Accepted 16 October 2020

\begin{abstract}
Purpose - This paper aims to systematically expound the theory and development background of supply chain finance and blockchain, design a railway freight supply chain financial platform based on blockchain, determine the risk management system and business support system of supply chain finance business and analyze the value generated by the combination of supply chain finance business and blockchain.

Design/methodology/approach - Investigation and research method; Prototype method; Model method; Value analysis.

Findings - The business model integrating supply chain finance and blockchain technology will bring great changes to freight industry. The development of supply chain finance is beneficial to the healthy development of the core participants of railway freight transport business and its upstream and downstream ecosystems. It links commerce, logistics, warehousing and financial services together and builds an industry-integrated ecological service platform through information technology platform and supporting system, taking data as the basis and combining information technology such as blockchain as innovative means.

Originality/value - This paper will provide important reference value for related research. This paper innovatively designs the supply chain financial platform of freight transportation industry-integrating blockchain technology and analyzes its business model, technical system, risk management and control system and value system in detail, which will provide technical support for the innovative reform of freight information technology and realize the stable and high-speed development of freight logistics informationization.
\end{abstract}

Keywords Blockchain, Supply chain finance, Freight transportation, Railway logistics

Paper type Research paper

Railway freight transportation urgently needs the vision of transforming into modern logistics and the government's policy support for the development of supply chain finance,

(c) Peng Xie, Qiang Chen, Ping Qu, Jianping Fan and Zhijun Tang. Published in Smart and Resilient Transportation. Published by Emerald Publishing Limited. This article is published under the Creative Commons Attribution (CC BY 4.0) licence. Anyone may reproduce, distribute, translate and create derivative works of this article (for both commercial and non-commercial purposes), subject to full attribution to the original publication and authors. The full terms of this licence maybe seen at http://creativecommons.org/licences/by/4.0/legalcode

This paper forms part of special section "Intelligent Technology and Application of Freight Railway", guest edited by Jiansheng Zhu, Ruimin Wang and Peng Xie.

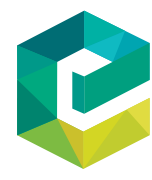

Smart and Resilient Transportation Vol. 2 No. 2,2020

Emerald Publishing Limited e-ISSN: 2632-0495 e-ISSN: 2632-0495 DOI 10.1108/SRT-09-2020-0007 
SRT

2,2

which has become a powerful driving force for railway enterprises to carry out supply chain financial services. Under the mode of supply chain management, enterprises gradually turn to cross-border integration, which makes the maintenance and management of customer relations become more and more important. Railway logistics enterprises can support professional financial operation through modern logistics services and make the relationship between upstream and downstream enterprises closer, thus being in a dominant position in the competition.

As the railway has the basic conditions for supply chain finance, such as warehouse, information system, logistics monitoring and personnel, developing supply chain finance business can improve the utilization rate of assets of railway enterprises, reduce idle assets and explore new profit sources, and developing supply chain finance can become a new profit growth point for railway enterprises. Innovative integration of logistics industry and financial industry can reduce not only customer transaction costs but also the risks caused by information asymmetry, and become an important business model of logistics enterprises. Cooperation in the freight supply chain will improve the efficiency of the whole supply chain, improve the economic and social benefits significantly and introduce new channels for enterprise financing. In addition, freight supply chain finance can bring lower production cost and efficient supply speed to the supply chain, improve the effectiveness of the whole supply chain process management, reduce the financing cost, accelerate the overall capital turnover rate of freight supply chain and provide a brand-new operation mechanism and method for capital flow and seamless connection, so as to truly realize the multi-flow integration of freight logistics, information flow, capital flow, people flow and business flow.

\section{Development status of supply chain finance and blockchain}

\subsection{Supply chain finance theory and development status}

Supply chain finance is a new direction of the development of supply chain management and financial theory in recent years. It is the latest developed effective means to solve the financing difficulties of small and medium-sized enterprises. From the bank level, supply chain finance is a professional field for commercial banks to carry out credit business, while from the enterprise level, it is a channel for enterprises, especially small and medium-sized enterprises, to carry out financing. Specifically, banks provide financing and other settlement and financial management services to core enterprises, and at the same time provide suppliers of these core enterprises with the convenience of timely receipt of loans, or provide advance payment and inventory financing services to their distributors. Simply put, supply chain finance is to speed up the cash flow of each enterprise in the supply chain through structured operation, so that enterprises can develop their business better and faster on the basis of reasonable control of financial costs. However, the definition of supply chain finance is very close to the traditional factoring business and consignment business, but there are obvious differences. Factoring and consignment business are just a simple trade financing product, whereas supply chain finance is reached between core enterprises and banks. It is a systematic financing arrangement for all member enterprises in the supply chain (Hua and Qiang, 2017; Gu Jing et al., 2017).

In the 21st century, supply chain finance has developed rapidly all over the world, and financing models, methods and products for different industries and different levels are constantly appearing. All kinds of enterprises, especially small- and medium-sized enterprises, actively participate in it, but it is only a new thing in practice and theory. At 
present, China's supply chain finance has developed rapidly, which can be summarized into two categories: bank operation and entity operation. First, bank supply chain finance, represented by Ping An Bank, China CITIC Bank, Minsheng Bank, Industrial and Commercial Bank, etc., intervenes and conducts business with traditional credit advantages such as customer resources and capital flow; second, e-commerce companies such as Alibaba, JD.COM Mall and Suning Tesco, as representatives, set up professional companies to provide financing for distributors by virtue of their advantages in commodity flow and information flow (Shiqing and Bin, 2013).

The development of supply chain finance has gone through the process of trade financing, logistics finance, $1+\mathrm{N}$ supply chain finance, $\mathrm{M}+1+\mathrm{N}$ supply chain finance. In recent years, with the help of digital means, it has evolved more diversified. From the perspective of the nature of pledge and the sequence of transaction scenarios of supply chain finance, the current models of supply chain finance are generally divided into three categories: accounts receivable for upstream enterprise financing, inventory based on logistics and transportation industry, and prepayment for downstream sales enterprises, from which dozens of specific application modes are derived. From the perspective of supply chain finance business model and operation platform subject, it can be divided into core enterprise mode, e-commerce mode, logistics company mode and third-party platform mode. The business process, participants, risk control points and other related contents of supply chain finance are different under different modes, reflecting the differentiation and diversification characteristics of supply chain financial business.

In recent years, the central and local governments have successively issued policies to support the development of Supply Chain Finance: in October 2017, the general office of the State Council issued the guiding opinions on actively promoting the innovation and application of supply chain finance; in July 2019, the banking and Insurance Regulatory Commission of the State Council issued the guiding opinions on promoting the supply chain financial services to the real economy, etc. The successive promulgation of these policies puts forward new requirements for the development of supply chain finance business and points out the direction for the development of business.

\subsection{Development status of blockchain technology}

As an integrated application of distributed data storage, point-to-point transmission, consensus mechanism, encryption algorithm and other technologies, blockchain is considered as a subversive innovation of computing mode after mainframe, personal computer and internet, which is likely to cause a new technological innovation and industrial change in the global scope. Blockchain technology originated from the groundbreaking paper Bitcoin: a Peer-to-Peer Electronic Cash System published by NakamotoS in 2008. In a narrow sense, blockchain is a kind of chain data structure that combines data blocks in a sequential way according to time sequence and is guaranteed by cryptography as an unalterable and unforgeable distributed ledger. Broadly speaking, blockchain technology is a new distributed infrastructure and computing paradigm, which uses block chain data structure to verify and store data, uses distributed node consensus algorithm to generate and update data, uses cryptography to ensure the security of data transmission and access, and uses intelligent contracts composed of automated script codes to program and operate data. Blockchain is a distributed data application system, which is not easy to tamper with, difficult to forge and traceable. The blockchain records all the information of transactions. Once the data enters the blockchain, it is difficult for even internal staff to make any changes without being discovered. This feature determines that it is inseparable from internet applications. The larger and richer the application scenarios are, the faster the 
development of blockchain technology and industry will be. At present, blockchain technology is called by many organizations as a major breakthrough technology to completely change the business and even the operation mode of institutions. At the same time, such as cloud computing, big data, Internet of Things, artificial intelligence and other emerging information technologies, blockchain technology is not a single information technology, but relying on existing technology, with original combination and innovation, so as to realize the functions that have not been realized before.

According to the current development of blockchain technology, blockchain technology will experience the blockchain 1.0 mode characterized by programmable digital cryptocurrency system, the blockchain 2.0 mode characterized by programmable financial system and the blockchain 3.0 mode characterized by programmable society.

At present, it is generally believed that blockchain technology is in the early stage of 2.0 mode. Bitcoin is one of the earliest and most successful applications of blockchain 1.0 mode, which not only provides distributed public account books for digital cash transactions, but also supports programmable scripts with limited capacity. Blockchain 2.0 mode aims at providing programmable infrastructure and supports saving calculation results in public ledger. The introduction of intelligent contract (or on-chain code) which can run automatically in blockchain network is a highlight. Intelligent contract is a program deployed on blockchain and can run automatically, which covers programming languages, compilers, virtual machines, events, state machines, fault-tolerant mechanisms, etc. Ethereum is a representative application of blockchain 2.0 mode (Jiehui et al., 2020).

\section{Analysis on the development of supply chain finance business in railway freight industry}

\subsection{Railway freight supply chain financial business development}

2.1.1 Financial development status of railway freight supply chain. In August, 2011, China Railway Modern Logistics Technology Co., Ltd. and Shenzhen Development Bank reached a cooperation intention, realizing the formal connection between the online supply chain financial system of Shenzhen Development Bank and China Railway Modern Logistics Management System, representing the arrival of the era of real-time data exchange between the supply chain financial system and logistics supervision system of domestic commercial banks. In 2018, the total freight volume of China's railways will be 4.026 billion tons. The intelligent railway supply chain will also promote the integration of trade and supply chain financial service systems directly related to the logistics service industry chain, and will obtain cross-border benefits through the integration of transportation, trade and finance. According to the long-term prospect in the Medium-and Long-Term Railway Network Planning, by 2030, internal and external interconnection, smooth inter-regional multichannels, high-speed railway connectivity in provincial capitals, rapid access to cities and counties will be basically realized, and the largest railway logistics network in China will be formed. Therefore, the railway logistics and freight transportation industry will inevitably play a great role in supporting the factor endowment in the future railway supply chain ecology (Fengmao, 2020; Tian, 2020).

The "integration of transportation, trade and finance" led by the railway network aims at the upstream and downstream supply chain systems of all kinds of production/commerce industry chains, and uses the railway network, railway logistics base and controllable pickup and delivery to "door-to-door" road freight enterprises, etc., forming an integrated system carrier of "transportation, storage and distribution", as a "1" core enterprise and a closed control platform system in the " $1+\mathrm{N}+\mathrm{X}$ " of supply chain finance, through systematic financial arrangements, we are deeply involved in various commercial enterprises and even 
production enterprises, forming an industrial chain ecology of "five flows in one" of business flow, information flow, capital flow, logistics and people flow, and using the blockchain and supply chain double-chain integration model. TOKEN is used to control the transportation/ trade cycle within the tax cycle, helping upstream and downstream enterprises in the chain to obtain more reasonable value-added profits and further enhance the supply chain stability of the industrial chain ecological closed loop (Sixin and Jun, 2017; Geng, 2014).

2.1.2 Analysis of business entities and business activities of railway freight supply chain. Based on the analysis of business entities and business activities in the supply chain of railway freight industry, we take railway coal transportation as an example to analyze business entities and business activities in the business chain:

- Background analysis of coal railway freight transportation business.

Construct the main business chain through three core enterprises: upstream coal production, midstream transportation and downstream coal consumption.

Core enterprises at different stages gather a number of small- and medium-sized enterprises with supply chains around them:

- Supply chain finance business scenario in coal railway freight transportation.

Small- and medium-sized enterprises around the supply chain of core enterprises at different stages include production, loading and unloading, transportation, warehousing and service.

For different types of small- and medium-sized enterprises, accounts receivable which can be used for financing are formed in the business dealings with core enterprises.

The supply chain finance business of railway freight industry will closely focus on all kinds of small-and medium-sized enterprises in the whole freight business chain and design corresponding business models to meet the financing needs of all kinds of enterprises.

\subsection{Supply chain financial business needs of various enterprises in freight chain}

Building a supply chain financial platform around the railway freight transport industry and forming integrated financial services such as centralized and unified logistics, information flow and capital flow will make it possible for all kinds of cooperative financial institutions (including factoring companies, banks, insurance companies, guarantee companies, etc.) and upstream and downstream enterprises in logistics and transportation to cooperate closely, and achieve a win-win result for all partners .It provides upstream and downstream enterprises with financial services such as procurement, distribution, collection, financing, settlement and insurance, effectively mobilizes the advantages of logistics resources and realizes the effective mobilization and monitoring of logistics, from controlling goods and transactions to controlling data and funds, realizing the comprehensive control of supply chain risks, and realizing the efficient and low-risk supply chain financial service capability.

Commodities in railway freight transportation industry are generally bulk commodities. Therefore, we take railway coal transportation as an example to elaborate various supply chain financial business models. The chain of supply chain financial value-added service system of railway coal freight industry is shown Figure 1.

As shown in Figure 1, there are many large, medium and small enterprises and many business scenarios derived from the upstream and downstream areas of the core railway freight enterprises. For the upstream coal production enterprises, to expand the coal sales business, a series of subsidiary enterprises such as loading and unloading, transportation 
SRT

2,2

and storage are needed to provide services for them; for the downstream coal enterprises, to expand production and purchase coal, they need a series of subsidiary enterprises such as loading and unloading, transportation, storage and so on to provide services for them. In the various production activities of many enterprises, a series of basic trade has been produced. Just like the small- and medium-sized enterprises in various industries in China, the smallscale and insufficient working capital also exist in the small-scale and insufficient working capital of the small-sized and medium-sized enterprises in the railway coal freight industry chain, which urgently need to solve the problems of capital shortage and high financing cost.

Focusing on the financing needs of various enterprises in the upstream and downstream of the railway coal freight industry chain, several types of supply chain financial business models are designed specifically: accounts receivable, financing on behalf of mining, and financing on consignment. In the supply chain financial management, the supply chain financial platform will provide goods warehousing and logistics management for all participants in the business ecosystem, provide financial intermediation for upstream and downstream enterprises, give full play to the advantages of all parties in the ecosystem and create value for all parties.

2.2.1 Accounts receivable financing. Taking the accounts receivable vouchers held by coal-producing enterprises as the subject matter (pledge or transfer), it provides enterprises with short-term financing business with a term not exceeding the aging of accounts receivable. In this business model, the responsibilities of the supply chain financial platform include: providing logistics and warehousing information services for banks and other funders and providing financing services for small- and medium-sized enterprises. For the credit line provided by banks and other funders, the supply chain financial platform provides online functions such as business management, process supervision and comprehensive information services.

2.2.2 Financing on behalf of procurement. Supply chain financial platform provides financing services for coal consuming enterprises with purchasing needs and also provides logistics services such as purchasing, transportation, warehousing supervision and distribution.

2.2.3 Generation of sales financing. Supply chain financial platform provides financing services for coal-producing enterprises with sales demand and also provides logistics services such as warehousing supervision, transportation and sales.

Figure 1.

Chain diagram of supply chain financial value-added service system of railway coal freight industry

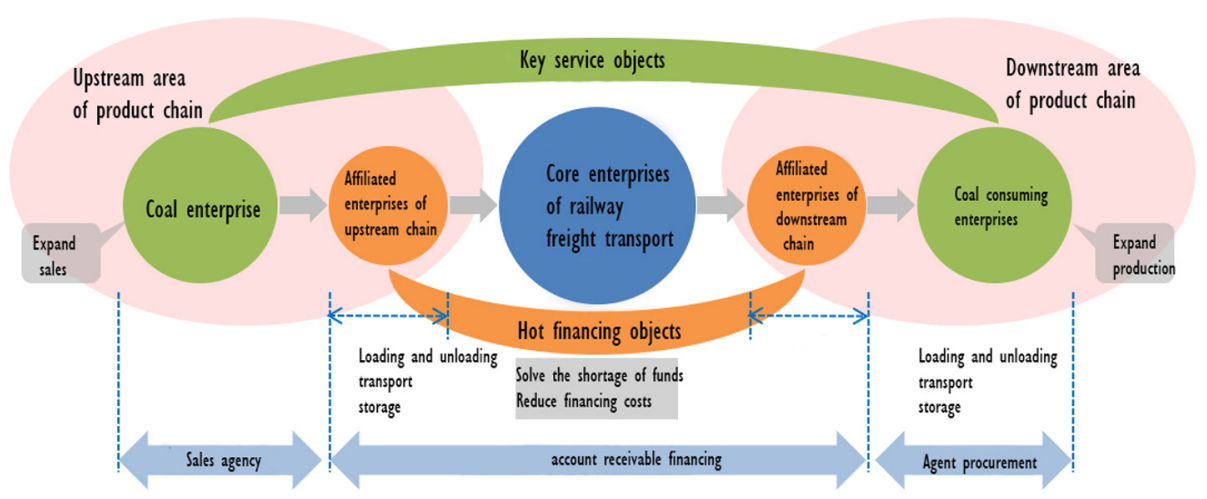




\subsection{Supply chain financial business development problem analysis and new technology}

integration

2.3.1 Analysis of the problems existing in the supply chain finance business of the railway freight industry. To promote the financial industry to improve its service capacity and support the industrial transformation and upgrading, in recent years, various ministries and commissions have successively formulated a series of relevant policies to encourage the development of supply chain finance business in various industries. However, there are still many problems and challenges in the development of traditional supply chain finance business, which are summarized as follows:

- There is an information island in the supply chain: ERP systems among enterprises in the same supply chain are not interoperable, which leads to information fragmentation among enterprises, and it is difficult to integrate information in the whole chain. For financial institutions such as banks, the opaque information of enterprises means that risk control is more difficult, which is a huge obstacle to corporate financing and penetration of financial institutions.

- Core enterprise credit cannot be transferred: the information island problem leads to the indirect trade information between upstream suppliers and core enterprises cannot be proved, while the traditional supply chain financial instruments have limited ability to transfer core enterprise credit, which leads to the core enterprise credit can only be transferred to the first-level supplier level, but cannot be transferred across the whole supply chain.

- The performance risk cannot be effectively controlled: the payment and agreed settlement between the supplier and the buyer, the financier and the financial institution are limited by the contractual spirit and the willingness to perform, and there are many uncertain factors, which may lead to misappropriation of funds, malicious default or operational risks.

2.3.2 Integration needs of blockchain technology and supply chain finance. The business pain point in the traditional supply chain finance scenario is the advantage of blockchain, a new technology. Blockchain is a fusion technology in many fields, such as point-to-point communication, digital encryption, distributed ledger, multi-party collaborative consensus algorithm, etc. It has the characteristics of unchangeable and traceable data on the chain, and is very suitable for multi-party supply chain financial business scenarios. Through blockchain technology, it can ensure data credibility and mutual recognition, transfer core enterprise credit, prevent performance risks, improve operational efficiency and reduce business costs. The application of blockchain in the field of supply chain finance can finally satisfy the mutual confirmation and matching of multiple information sources in the supply chain, and solve the pain point that the funder distrusts the transaction data (Xingxiong et al., 2018). Specific instructions are as follows:

- Transaction confirmation based on encrypted data.

Intangible assets that are difficult to supervise and protect under the network environment, blockchain is based on timestamp technology and difficult to tamper with, which has become a new method of intellectual property protection under the virtual environment. In recent years, it has begun to show important application value in the field of asset management, which promotes the real-time confirmation, authorization and transaction supervision of various assets. For tangible assets, such as certificates of deposit, accounts receivable and digital intelligent assets, real-world asset transactions can be realized under 
virtual environment, such as asset authorization and use control, product traceability and other applications. Blockchain realizes the automatic confirmation of movable property rights for all participants in the supply chain, forms an unalterable rights account book, and solves the pain points in the existing rights registration and rights realization:

- Proof of transaction authenticity based on deposit certificate.

The proof of transaction authenticity needs to be recorded in the creditor's rights information in the virtual world, and the consistency between the virtual information and the real information must be guaranteed, which is the basis of financial services and risk control. Supply chain finance needs to ensure that participants, transaction results and documents are based on real asset transactions. The authenticity of transaction is verified by manual means, which has some disadvantages such as high cost and low efficiency. To solve one of the core problems of supply chain finance, that is, the authenticity of transactions, it is necessary to obtain all kinds of information dynamically and in real time from the trading network under the virtual environment, and to carry out "cross-validation" of information to test the authenticity of transactions, which has become one of the key technologies of supply chain finance at present. Blockchain can solve this problem to a certain extent through digital signature, encryption and decryption technology and various offline operations:

- Credit disassembly based on shared ledger.

The goal of supply chain finance is to fully cover the financing of small and medium-sized enterprises. However, the financing needs of a large number of second-level and thirdlevel suppliers/distributors are still difficult to meet. How to provide financial services for a large number of non-first-level suppliers and distributors in core enterprises needs to be focused on. Blockchain technology can disassemble the credit of core enterprises and pass it on to suppliers and distributors in the whole chain through shared books. Core enterprises can register their creditor's rights and debts with suppliers on the blockchain platform, and transfer relevant accounting vouchers step by step. The original debtor of the accounting voucher is the core enterprise, so in the financing scenario of the bank or factoring company, the process of reviewing the trade background can be seen at a glance on the platform. The problem of credit transmission can be solved with the help of blockchain technology:

- Automatic execution based on intelligent contract.

Intelligent contract provides an automatic operation tool for the implementation of supply chain financial business, and relying on efficient, accurate and automatic contract execution, it can alleviate the problem of difficult contract execution in reality. Taking real right financing as an example, after delivery, payment instructions can be sent to banks through smart contracts, thereby automatically completing fund payment, liquidation and financial reconciliation, improving business operation efficiency and reducing potential risks and losses caused by human operations to a certain extent. At present, the intelligent contract development platforms mainly include: Hyperledger (Linux), Corda intelligent contract platform (R3 Alliance), Ethereum intelligent contract platform, etc. Hyperledger (Linux) is widely used in commercial projects.

2.3.3 Integration framework of blockchain and supply chain finance. The overall structure based on the integration of blockchain and supply chain financial business is shown in Figure 2. 
Among them, the supply chain financial platform is the platform to be built by the railway freight logistics industry; Other partner systems are the systems of relevant external partners. The blockchain platform is built with Hyperledger-based Fabric technology. Each module inside the blockchain platform is described as follows.

$A P I+S D K$ : External business systems access various resources in the blockchain platform network through SDK packaged into API interface, including account books, transactions, chain codes, events, rights management, etc., especially the installation, instantiation, upgrade and call of chain codes.

Account book: it is the core structure, which is responsible for recording application information, and the application records data in the account book by initiating transactions; Transaction: the logic of execution is carried by chain code; Events: Events occurring in the whole network operation can be accessed by applications to trigger external processes and even other systems; Chain code: relying on container, state machine and other technologies. User chain code provides state processing logic based on blockchain distributed ledger, which is written in Go/Java language and runs in Docker container.

Books and transactions depend on core technologies such as blockchain structure, database and consensus mechanism. Sorting service: All transactions in the sending network need to be sorted globally by sorting service before being verified and accepted by Committer, which provides atomic broadcast sorting function.

Authority management: responsible for access control in the whole process, solving the problem of who allows an operation in a certain scenario and using existing public key infrastructure system, digital certificate, encryption and decryption algorithm and other security technologies.

The bottom layer is composed of multiple nodes in peer-to-peer network, which communicates among different components through google remote procedure call channel, and uses Gossip protocol to provide message transmission, block distribution and state synchronization among nodes.

\section{Design of supply chain financial platform for railway freight industry based on blockchain}

\subsection{Supply chain financial platform architecture design}

According to the basic processing ideas for blockchain integration of supply chain finance business and the characteristics of railway freight industry, the overall design of supply chain finance platform for railway freight industry based on blockchain is shown in Figure 3.

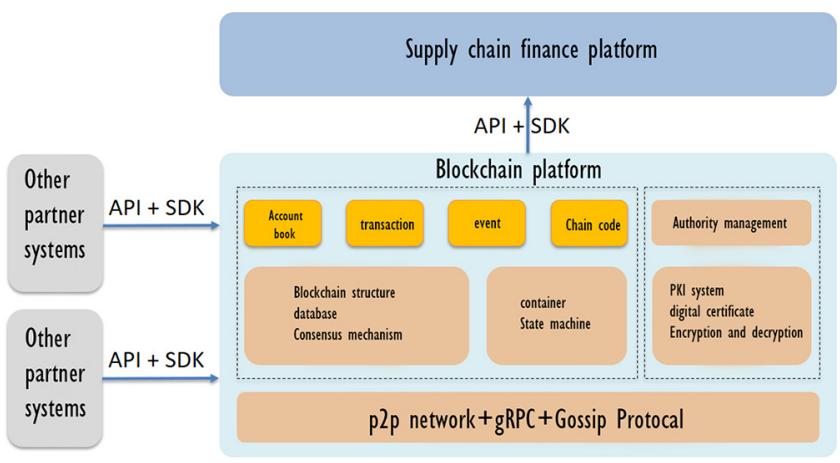

Figure 2.

Integrated architecture diagram of blockchain and supply chain financial business 


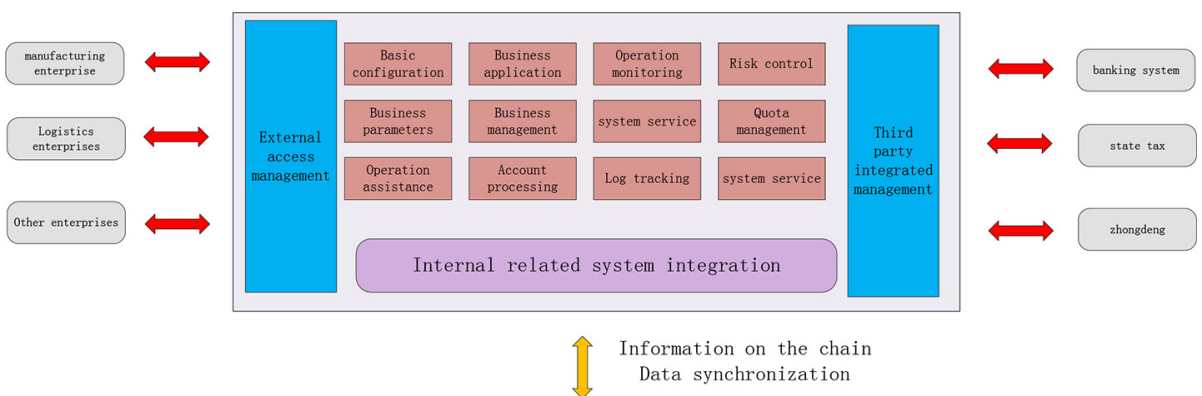

Figure 3.

Overall architecture diagram of supply chain financial platform

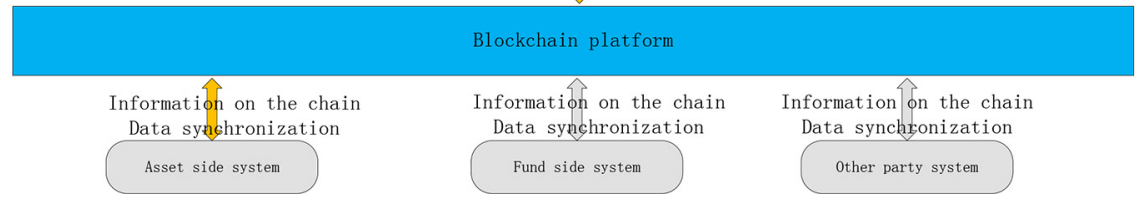

The overall architecture of the platform includes supply chain financial platform, internal related system integration, external access management, third-party integrated management, uplink processing with blockchain platform and data synchronization:

- Supply chain financial platform: To realize various business management functions of supply chain financial business, Including the application and initiation of various businesses, subsequent business acceptance and handling, management of various financing activities, risk control quota management and basic business support management functions.

- Integration of internal related systems: Realize the integrated management of related systems such as customers and merchants, freight transportation and logistics related to the railway, and realize the information sharing between internal data and supply chain financial platform.

- External access management: To realize data access and sharing transmission with external production enterprises, logistics enterprises and other enterprises.

- Third-party integrated management: To realize the integrated management with banking system, national tax system, Zhongdeng system, etc. necessary for the development of supply chain finance business.

- Interaction with blockchain platform: Realize the blockchain deposit, certification and uplink function of business data and document data by all parties involved in the business of supply chain financial platform through blockchain technology.

- Other external systems: For all kinds of external cooperation entities, such as asset side, capital side and other parties, access the platform according to the access specification of blockchain platform, so as to realize the synchronization of information chain and data.

\subsection{Design of risk management and control system}

In the field of supply chain finance, risk management has always been an important topic, and a perfect risk management system is an important factor in establishing the business model of supply chain finance. In the supply chain financial risk management system, new 
technologies such as big data, Internet of Things, artificial intelligence and corporate portraits should be used to obtain more timely and accurate data of the controlled objects and comprehensively identify, analyze and finely control various risks related to supply chain finance. The management of risk control should run through all links before, during and after lending: in the pre-lending link, corporate credit rating can assist financial institutions to conduct corporate credit operations and quota management for certain financing products. In the process of signing and lending in the loan, the examination and approval will be carried out according to the credit and quota in the pre-loan process. For the chain post-loan management link, the risk control system can monitor all kinds of information of the borrower in multiple dimensions and in real time and promptly and actively push the relevant personnel about the risk events and early warning reminders of the enterprise after discovering the risk events (Bin et al., 2016; Jinzhao and Ju'e, 2015).

3.2.1 Risk identification and analysis. Typical risks faced by railway freight transport industry in developing supply chain finance business include the following:

- Fraud risk. This risk is reflected in the authenticity of the basic transactions on which the supply chain financial business depends, including possible fraudulent behaviors such as constructing false transactions between buyers and sellers, or enterprises that do not have financing conditions pretending to be enterprises of the supply chain financial transaction parties to apply for financing, or using false information such as enterprises and transactions to apply for financing.

- Credit risk. According to the historical transaction records and business habits of enterprises participating in supply chain finance business, check the repayment performance of financing entities and repayment enterprises, and check the bad records of the entities through third parties (such as national tax, courts, etc.), so as to comprehensively judge the credit status of the participants in supply chain finance business, thus providing good basic data support for risk management and control.

- Risks such as price fluctuation of pledge. For the financing of goods, we should pay attention to the risks of the pledge itself, especially the position risk of the price fluctuation of the pledge after lending. The market price of the pledge may be affected by many factors and fluctuate. Therefore, the risks brought by the price fluctuation of pledge will be the key risks of the supply chain finance business of goods rights.

3.2.2 Design of wind control model. Compared with traditional financial business, the risk control management of supply chain financial business should pay attention to not only the risks of financing subjects but also the final repayment sources, so as to control the risks of financing business in all directions. The wind control management model given in this study is shown in Figure 4:

- Risk control management is divided into three stages, namely, paying attention to the preliminary screening and review of basic transactions and assets in the prelending stage, paying attention to the rating credit and use of financing entities and related participants in the middle lending stage, paying attention to the repayment of various financing businesses after lending, monitoring related parties and collecting due claims.

- Risk control information focuses on three dimensions and six aspects of information, namely, enterprise basic information, enterprise shareholder information and enterprise operation information, and six aspects, namely, 
Figure 4.

Wind control management model diagram

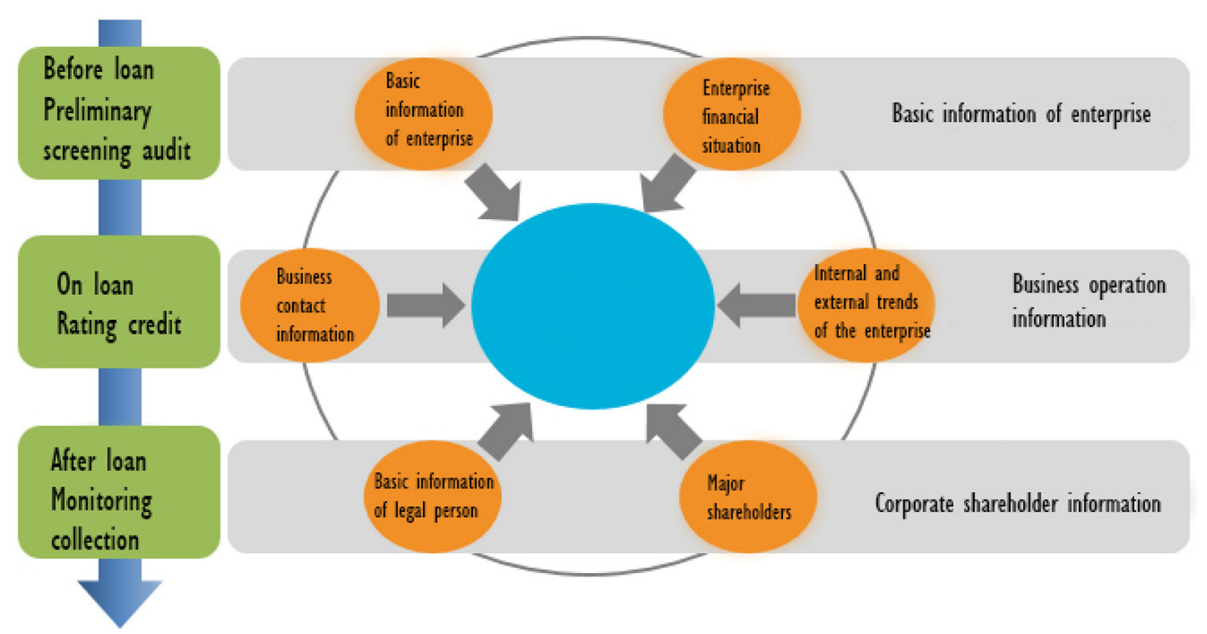

enterprise basic static information, enterprise financial status, legal person basic information, major shareholder information, enterprise exchange information and internal and external dynamic information. By collecting information about different dimensions and aspects of financing entities and final repayment entities, we can determine the credit line basis of enterprises, judge the current state of enterprises and predict the future dynamic information of enterprises, so as to better manage risk control.

- Multi-dimensional and multi-factor weighted risk control model algorithm, which classifies various types of risk control information for risk control management, gives different weights to different types of information in calculation, and can customize the risk factors and the scores of each factor under various types of information. The enterprise information that meets the requirements of risk factor data can finally get the total score of the enterprise under this model through this model algorithm.

The overall model is described as follows:

- Multi-dimensional model division and weight setting of each dimension. Support the establishment of multiple wind control models. Different dimensions can be set for a certain wind control model, and different dimensions are allowed to set their own risk factors. The model adopts a 100-point system, assuming that the weight of a certain dimension $\mathrm{m}$ in the model is $n$, the model has $\mathrm{k}$ dimensions, and the weight of each dimension is $100 \%$. Therefore, the calculation algorithm of the first-level dimension framework of the model is described as follows:

Total score of model

For example, for the $\mathrm{P}$ model, three dimensions of enterprise basic information $\mathrm{A}$, enterprise shareholder information $\mathrm{B}$ and enterprise management information $\mathrm{C}$ are set, and the full score of each dimension is 100 points. The weights of $\mathrm{A}, \mathrm{B}$ and $\mathrm{C}$ are set to $30 \%, 30 \%$ and $40 \%$ respectively. It is necessary to calculate the scores of $\mathrm{A}, \mathrm{B}$ and $\mathrm{C}$, respectively, and the overall score is: A according to the first-level dimension framework. 
- Setting multiple risk factors in each dimension. Set the risk factors included in each dimension of a wind control model and their weights under this dimension. Take the previous example: for example, dimension $\mathrm{A}$ includes two risk factors $\mathrm{A}$ and $\mathrm{B}$ (each with a weight of 50\%), Dimension B includes four risk factors C, D, E and F (each with a weight of $25 \%$ ), and Dimension $\mathrm{C}$ includes five risk factors $\mathrm{G}, \mathrm{H}, \mathrm{I}$, J and $\mathrm{K}$ (each with a weight of $20 \%$ ). So far, a basic risk control model system with three dimensions and eleven risk factors has been established.

- Preparation of business data input. According to all kinds of information of y enterprise in three dimensions of $\mathrm{a}, \mathrm{b}$ and $\mathrm{c}$, the business data required by eleven risk factors (i.e., a, b, c, d, e, f, g, h, I, j and k) required by the risk control model are extracted, so as to facilitate the calculation through the risk control model.

- Operational processing of wind control model. According to the data of eleven risk factors that $\mathrm{Y}$ enterprise meets the requirements, input the data into the wind control model, and calculate the final score of each risk factor according to the rules corresponding to different data scores specified in different risk factors in the model, and give the final scores of each dimension after the model operation. To take the above example: the input data based on eleven risk factors (i.e., A, B, C, D, E, F, G, H, $\mathrm{I}, \mathrm{J}, \mathrm{K}$ ) and the operation and judgment process of risk control model judgment rules are shown in the following table: (Table 1).

- Wind control score output. Y enterprise score calculation is as follows:

$$
\begin{aligned}
& \text { Y total score of enterprise model }= \\
& \quad=\mathrm{A} * 30 \%+\mathrm{B} * 30 \%+\mathrm{C} * 40 \% \\
& \quad=70 * 30 \%+60 * 30 \%+80 * 40 \% \\
& \quad=71
\end{aligned}
$$

According to the final risk control score of enterprise Y, 71 points will be scored, and then follow-up business management activities such as credit rating and quota management related to supply chain finance business will be carried out.

\section{Value analysis of the combination of supply chain finance business and blockchain}

\subsection{Value brought to external partners}

Supply chain finance business integrates business flow, people flow, logistics flow, information flow, capital flow and other data into the chain by using blockchain technology, realizing the integration of "five flows", ensuring data security and realizing transparent visualization of data business. Buyers and sellers can better grasp the tracking logistics

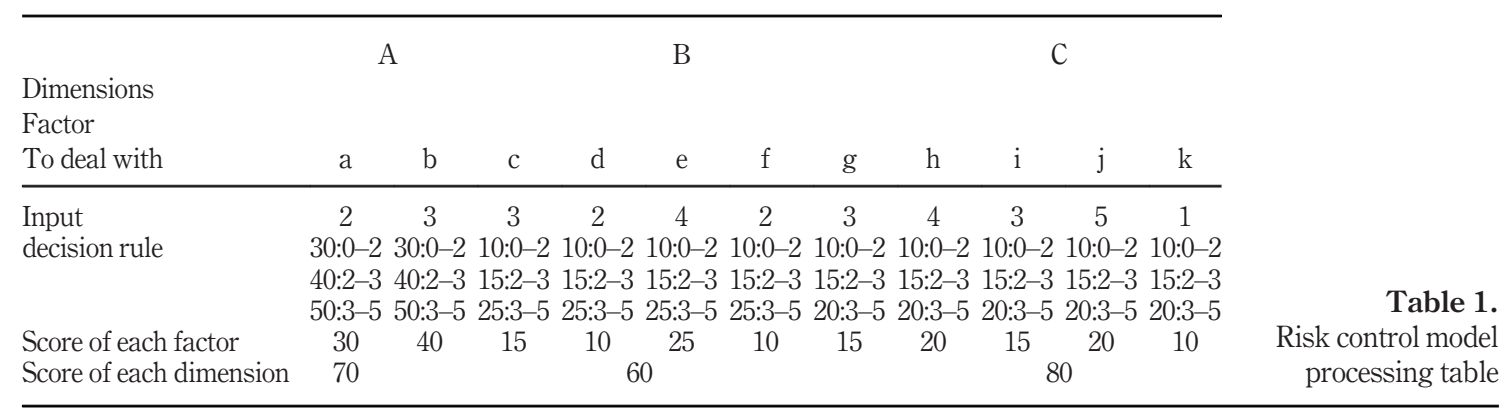


SRT

2,2

82

information and reduce the risks of both parties through intelligent contract technology. Give full play to the divisible, traceable and tamperable features of blockchain technology. Core enterprises issue digital payment commitments to tier-one suppliers in blockchain, and tier-one suppliers can split the above commitments and transfer some of them to tier-two and tier- $n$ suppliers according to settlement needs. Supply chain finance business takes advantage of blockchain consensus mechanism and cross-validation can ensure business authenticity and prevent fraud risks. At the same time, the traceability of blockchain technology should be brought into full play, so as to achieve one-to-one correspondence between receivable financing and basic business.

The traditional business process of confirming rights is complicated and takes a long time, which affects the borrower's experience. Issue digital assets based on blockchain, digitalize the rights and interests of accounts receivable, and ensure the true expression of debt subject by encryption, which is convenient for the division, circulation and confirmation of rights and interests of accounts receivable, improves the liquidity of accounts receivable and optimizes business processes and customer experience.

\subsection{Value for railway freight industry}

Railway transportation, as the artery of China's national economy and a popular means of transportation, has achieved remarkable results after years of informatization construction. It has established an integrated information integration platform and a number of business information systems covering passenger and cargo services, operation and management, dispatching and command, safety monitoring and other fields. Based on massive data assets, it has carried out innovative applications of big data and artificial intelligence technology, and accumulated sufficient technical foundation for the application of blockchain technology. At the same time, China's railways are also facing the challenges of reducing costs and increasing efficiency under the new situation. The railway system is large in scale, long in business chain and involved in many fields. The use of blockchain technology can reduce the cost of supervision and management, help to reduce the overall cost of passenger and freight transportation of railways and even the whole society, and promote the high-quality development of railways in the new era.

At present, the application of blockchain technology is expanding from the financial field to other fields, and many industries are in the exploratory stage I $n$ essence, railway transportation is a multi-flow transportation organization mode, such as people flow, goods flow, car flow, information flow and capital flow. It is urgent to apply blockchain technology to realize trust, traceability and contract intelligence in the whole process of railway transportation.

\section{Conclusion}

The development of supply chain finance is beneficial to the healthy development of the core participants of railway freight transport business and its upstream and downstream ecosystems. It links commerce, logistics, warehousing and financial services together, and builds an industry integrated ecological service platform through information technology platform and supporting system, taking data as the basis and combining information technology such as blockchain as innovative means.

In an era when the whole society is vigorously advocating and gradually moving towards digital economy, all walks of life are seeking comprehensive digital transformation, transforming and reconstructing traditional businesses through technological innovation, injecting new kinetic energy into railway business expansion and cross-border integration and even the value enhancement of the whole industry. At the same time, emerging 
technologies represented by blockchain provide the underlying support for the development and innovation of information technology platforms, creating favorable conditions for the construction of integrated platform operation with "scenario-business-product-data". In the aspect of extended value-added services for freight transportation, this paper innovatively designs the supply chain financial platform of freight transportation industry integrating blockchain technology and analyzes its business model, technical system, risk management and control system and value system in detail, which will provide technical support for the innovative reform of freight information technology and realize the stable and high-speed development of freight logistics informationization.

\section{References}

Bin, Y., Weiming, Z. and Haiying, Z. (2016), "Research on supplier-led supply chain finance model", Financial Research, No. 12, pp. 175-190.

Fengmao, S. (2020), "Application of blockchain technology in supply chain finance", Computer Products and Circulation, No. 8, p. 70.

Geng, L. (2014), "Analysis of B2C supply chain financial model in the era of internet finance", Times Finance, No. 2, pp. 67-69.

Hua, S. and Qiang, L. (2017), "Supply chain financial model innovation based on virtual industrial cluster: a case study of Chuangjie company", China Industrial Economy, No. 5, pp. 172-192.

Jiehui, L., Yan, J. and Limin, C. (2020), "Zheng Xiaozhen. Research on innovation of supply chain financial model driven by blockchain technology", Journal of Fujian Financial Management Cadre Institute, No. 2, pp. 14-20.

Jing, G., Xiang, C. and Xiang, D. (2017), "Research on innovation of supply chain financial model of SMEs", Soft Science, Vol. 31 No. 2, pp. 83-86+97.

Jinzhao, S. and Ju'e, G. (2015), "Research on the development of supply chain finance model and domestic practice from the perspective of internet", Journal of Xi 'An Jiaotong University (Social Science Edition), Vol. 35 No. 4, pp. 10-16.

Shiqing, X. and Bin, H. (2013), "Analysis of three typical models of international supply chain finance", Economic Theory and Economic Management, No. 4, pp. 80-86.

Sixin, X. and Jun, Y. (2017), Strategic Choice for Railway Enterprises to Develop Supply Chain Finance. railway Purchase and Logistics, Vol. 12 No. 4, pp. 30-33.

Tian, L. (2020), "Based on 'blockchain+supply chain finance', the financing problem of SMEs is explored", Peasant Staff, No. 11, pp. 175-+181.

Xingxiong, Z., Qingsu, H. and Shanqi, G. (2018), "Application of blockchain technology in supply chain finance”, China Circulation Economy, Vol. 32 No. 3, pp. 111-119.

\section{Further reading}

An, L.Y., Jian, Z. and Rong, A. (2019), "Research on the optimization of supply chain financial system based on blockchain technology", Southwest Finance, No. 1, pp. 72-79.

Fangzhi, F., Guoqiang, S. and Xiaoyan, W. (2017), "Research on credit risk evaluation and risk management of SMEs under supply chain finance model", Journal of Central University of Finance and Economics, No. 12, pp. 34-43.

Hao, J. and Wei, G. (2019), "Research on the application of new supply chain financial model in financing of small and micro enterprises", Southwest Finance, No. 4, pp. 46-52.

He, Y., Zhao, Y. and Tsui, K.L. (2019), "Exploring influencing factors on transit ridership from a local perspective", Smart and Resilient Transport, Vol. 1 No. 1. 
SRT

2,2

84

Minfeng, L. (2020), "Research on the application of financial technology in supply chain financial risk management", Journal of Hubei University of Economics, Vol. 18 No. 1, pp. 67-73.

Rui, W. and Jintang, D. (2018), "Supply chain finance in internet plus: new ideas for SME financing", Enterprise Economics, Vol. 37 No. 2, pp. 108-114.

Shi, L., Jia, Z., Sun, H., Tian, M. and Chen, L. (2020), “Analysis of the factors influencing on bird nesting and its impact on railway operation", Smart and Resilient Transport.

Wang, Y., Wei, Y., Shi, H., Liu, X., Feng, L. and Shang, P. (2019), "The unit train make-up scheme for loaded direction in the heavy haul railway", Smart and Resilient Transport, Vol. 1 No. 1.

Ying, G. and Zhilai, Z. (2020), "Innovation of financing mode and path for small and micro enterprises under the background of blockchain finance [J/OL]", contemporary economic management: 1-10 [2020-07-21], available at: http://kns.cnki.net/kcms/detail/13.1356.f.2020

\section{Corresponding author}

Ping Qu can be contacted at: zhipengli2012@foxmail.com

For instructions on how to order reprints of this article, please visit our website: www.emeraldgrouppublishing.com/licensing/reprints.htm

Or contact us for further details: permissions@emeraldinsight.com 